\title{
Density functional theory study on the $B$ doping and B/P codoping of Si nanocrystals embedded in $\mathrm{SiO}_{2}$
}

\author{
Zhenyi Ni (倪朕伊), ${ }^{1}$ Xiaodong Pi (皮孝东) ${ }^{1,}{ }^{*}$ Stefaan Cottenier,${ }^{2}$ and Deren Yang $(\text { 杨德仁) })^{1, \dagger}$ \\ ${ }^{1}$ State Key Laboratory of Silicon Materials and School of Materials Science and Engineering, Zhejiang University, \\ Hangzhou, Zhejiang 310027, China \\ ${ }^{2}$ Center for Molecular Modeling and Department of Materials Science and Engineering, Ghent University, \\ Technologiepark 903, BE-9052 Zwijnaarde, Belgium
}

(Received 22 October 2016; revised manuscript received 19 January 2017; published 21 February 2017)

\begin{abstract}
Doping silicon nanocrystals ( $\mathrm{Si} \mathrm{NCs)} \mathrm{embedded} \mathrm{in} \mathrm{silicon} \mathrm{dioxide}\left(\mathrm{SiO}_{2}\right)$ with boron $(\mathrm{B})$ and phosphorus $(\mathrm{P})$ is a promising way of tuning the properties of Si NCs. Here we take advantage of density functional theory to investigate the dependence of the structural and electronic properties of $\mathrm{Si} \mathrm{NCs}$ embedded in $\mathrm{SiO}_{2}$ on the doping of B and P. The locations and energy-level schemes are examined for singularly B-doped or B/P-codoped $\mathrm{Si}$ NCs embedded in $\mathrm{SiO}_{2}$ with a perfect or defective $\mathrm{Si} / \mathrm{SiO}_{2}$ interface at which a $\mathrm{Si}$ dangling bond exists. A dangling bond plays an important role in the doping of $\mathrm{Si} \mathrm{NCs}$ with $\mathrm{B}$ or B/P. The doping behavior of $\mathrm{B}$ in $\mathrm{Si}$ $\mathrm{NCs}$ embedded in $\mathrm{SiO}_{2}$ vastly differs from that of $\mathrm{P}$. The electronic structure of a $\mathrm{B} / \mathrm{P}$-codoped $\mathrm{Si}$ NC largely depends on the distribution of the dopants in the NC.
\end{abstract}

DOI: 10.1103/PhysRevB.95.075307

\section{INTRODUCTION}

Silicon nanocrystals ( $\mathrm{Si} \mathrm{NCs}$ ) have been intensively investigated during past decades for their promising applications in various fields such as optoelectronics [1-6], photovoltaics [7-11], energy storage [12,13], and bioimaging $[14,15]$. This is mainly due to their nontoxicity, low cost, and compatibility with well-established Si-based microelectronic technology. It has been recently shown that doping is a critical means to realize the full potential of Si NCs [16-19]. For example, low-energy light emission related to the transitions of electrons from the band edge to the defect state has been observed in boron (B)- and phosphorus (P)-doped Si NCs [20-23], leading to enhanced tunability of the light emission from Si NCs. In addition, heavy B and P doping have enabled localized surface plasmon resonance (LSPR) for Si NCs [2428]. A series of novel devices that take advantage of the dopinginduced properties of Si NCs are now highly expected. Among a variety of matrices in which $\mathrm{Si}$ NCs can be embedded, $\mathrm{SiO}_{2}$ is very popular because of the excellent availability of $\mathrm{SiO}_{2}$ and the high-quality interface between $\mathrm{Si} \mathrm{NCs}$ and $\mathrm{SiO}_{2}$ [29-31]. Therefore, the doping of Si NCs embedded in $\mathrm{SiO}_{2}$ deserves careful investigation during the course of advancing Si-NC-based technology.

In contrast to the doping of hydrogen-passivated Si NCs, the doping of $\mathrm{Si} \mathrm{NCs}$ embedded in $\mathrm{SiO}_{2}$ has not been systematically simulated because complicated models need to be used in the simulation [32-35]. Guerra and Ossicini [36] and Carvalho et al. [37] investigated the doping of B and $\mathrm{P}$ in $\mathrm{Si} \mathrm{NCs}$ that were passivated by $\mathrm{OH}$ groups. However, the absence of the $\mathrm{Si} / \mathrm{SiO}_{2}$ interface in their $\mathrm{OH}$-terminated Si NC models was somehow far away from the routinely encountered situation. We have recently managed to simulate the $\mathrm{P}$ doping of $\mathrm{Si} \mathrm{NCs}$ embedded in $\mathrm{SiO}_{2}$ by constructing $\mathrm{SiO}_{2}$-coated Si NCs [38]. The results highlighted the difference

\footnotetext{
*Corresponding author: xdpi@zju.edu.cn

${ }^{\dagger}$ Corresponding author: mseyang@zju.edu.cn
}

in the distribution of $\mathrm{P}$ and the electronic properties between hydrogen-passivated $\mathrm{Si}$ NCs and those with oxide at the surface $[38,39]$. Now we further investigate the $\mathrm{B}$ doping and $\mathrm{B} / \mathrm{P}$ codoping of $\mathrm{Si}$ NCs embedded in $\mathrm{SiO}_{2}$ in the framework of density functional theory (DFT). The model of a Si NC embedded in $\mathrm{SiO}_{2}\left(\mathrm{Si} @ \mathrm{SiO}_{2}\right)$ is constructed by coating a 1.4-nm Si NC with a monolayer of $\mathrm{SiO}_{2}(0.25 \mathrm{~nm}$ thick), which is itself passivated by hydrogen. It has been already demonstrated that the rather thin $\mathrm{SiO}_{2}$ layer is able to model the matrix-induced strain as well as the defective $\mathrm{Si} / \mathrm{SiO}_{2}$ interface $[38,40]$. For all NC models that are constructed this way, a full geometry optimization is performed. The locations and energy-level schemes are examined for B-doped or $\mathrm{B} / \mathrm{P}$ codoped $\mathrm{Si} \mathrm{NCs}$ embedded in $\mathrm{SiO}_{2}$ with a perfect or defective $\mathrm{Si} / \mathrm{SiO}_{2}$ interface. It is found that the $\mathrm{B}$ doping vastly differs from the $\mathrm{P}$ doping for $\mathrm{Si} \mathrm{NCs}$ embedded in $\mathrm{SiO}_{2}$. We also show that the electronic structures of B/P-codoped Si NCs embedded in $\mathrm{SiO}_{2}$ are closely related to the distribution of the dopants.

\section{METHOD}

The optimization of structures and the calculation of total energies are performed at $0 \mathrm{~K}$ by using the all-electron DFT modeling package DMol3 [38,41,42]. The Becke-LeeYang-Parr (BLYP) exchange-correlation functional at the generalized gradient approximation (GGA) level is used. Double numerical basis sets augmented with $p$-polarization functions (DNP basis sets) are employed as the atomic orbital basis functions. To ensure accurate calculation, a high selfconsistent field (SCF) convergence threshold of $10^{-6}$ and a large orbital cutoff of $4.6 \AA$ are employed. The maximum energy change and forces on all of the atoms in the optimized structures are less than $10^{-5} \mathrm{Ha}$ and $0.002 \mathrm{Ha} / \AA$, respectively. To prevent the optimizer from taking unreasonable steps, the maximum allowed change of any Cartesian coordinate during the structural relaxation is less than $0.3 \AA$. The highest occupied molecular orbital (HOMO), highest occupied deep energy level (HODE), lowest unoccupied deep energy level (LUDE), and lowest unoccupied molecular orbital (LUMO) are sampled on a grid with a spacing of $0.2 \mathrm{~A}$. 

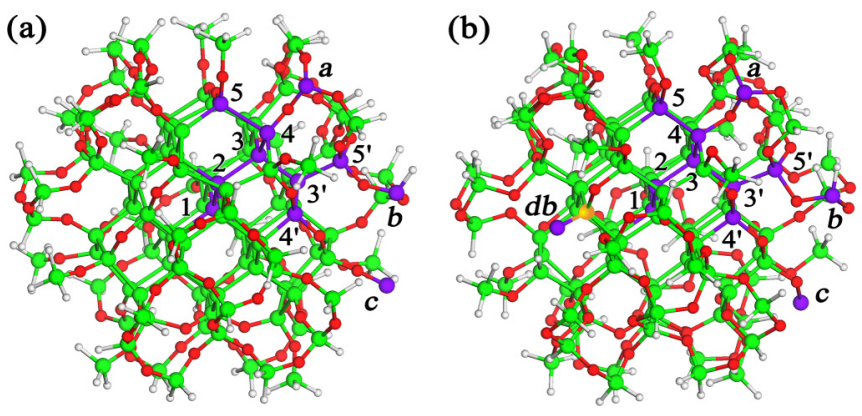

FIG. 1. Model of an optimized 1.4-nm Si NC embedded in $\mathrm{SiO}_{2}$ with an (a) perfect $\mathrm{Si} / \mathrm{SiO}_{2}$ interface $\left(\mathrm{Si} @ \mathrm{SiO}_{2}, \mathrm{Si}_{123} \mathrm{H}_{100} \mathrm{O}_{96}\right)$ or (b) defective $\mathrm{Si} / \mathrm{SiO}_{2}$ interface at which a $\mathrm{Si}$ dangling bond exists ( $\mathrm{Si} @{ }_{d b} \mathrm{SiO}_{2}, \mathrm{Si}_{123} \mathrm{H}_{101} \mathrm{O}_{95}$ ). $\mathrm{Si}, \mathrm{H}$, and $\mathrm{O}$ atoms are denoted by green, gray, and red balls, respectively. A Si atom initially with a dangling bond at the $\mathrm{Si} / \mathrm{SiO}_{2}$ interface is highlighted by an orange ball. A substitutional or passivating $\mathrm{B}$ atom is indicated by a violet ball. $\mathrm{B} 1, \mathrm{~B} 2, \mathrm{~B} 3\left(\mathrm{~B} 3^{\prime}\right), \mathrm{B} 4\left(\mathrm{~B} 4^{\prime}\right)$, and $\mathrm{B} 5\left(\mathrm{~B}^{\prime}\right)$ result from moving a substitutional $B$ atom along the path of $1 \rightarrow 2 \rightarrow 3\left(3^{\prime}\right) \rightarrow 4\left(4^{\prime}\right) \rightarrow 5$ $\left(5^{\prime}\right)$. When a $\mathrm{B}$ atom replaces a $\mathrm{Si}$ atom connected to one, two, or three $\mathrm{H}$ atoms at the surface, it is denoted as $\mathrm{B}_{a}, \mathrm{~B}_{b}$, or $\mathrm{B}_{c}$, respectively. As a $\mathrm{B}$ atom passivates a $\mathrm{Si}$ dangling bond at the $\mathrm{Si} / \mathrm{SiO}_{2}$ interface, it is denoted as $\mathrm{B}_{d b}$.

\section{B DOPING}

\section{A. Formation energy}

Figure 1 shows the model of a geometry-optimized 1.4-nm $\mathrm{Si} \mathrm{NC}$ embedded in $\mathrm{SiO}_{2}$ with (a) perfect $\mathrm{Si} / \mathrm{SiO}_{2}$ interface $\left(\mathrm{Si} @ \mathrm{SiO}_{2}\right.$ ) or (b) defective $\mathrm{Si} / \mathrm{SiO}_{2}$ interface at which a $\mathrm{Si}$ dangling bond exists $\left(\mathrm{Si} @{ }_{d b} \mathrm{SiO}_{2}\right)$. The model of $\mathrm{Si} @ \mathrm{SiO}_{2}$ is based on a 1.4-nm H-passivated Si NC $\left(\mathrm{Si} @ \mathrm{H}, \mathrm{Si}_{71} \mathrm{H}_{84}\right)$, which has been detailed in our previous work [43-47]. An $\mathrm{O}$ atom is used to replace every $\mathrm{H}$ atom in $\mathrm{SiH}$ and $\mathrm{SiH}_{3}$ at the surface of $\mathrm{Si} @ \mathrm{H}$, which is then outwardly bonded to an added $\mathrm{Si}$ atom. One $\mathrm{O}$ atom is inserted bewteen two $\mathrm{Si}$ atoms in the neighboring $\mathrm{SiH}_{2}$ due the fact that the room between neighboring $\mathrm{SiH}_{2}$ may be too small to accommodate both added $\mathrm{O}$ and $\mathrm{Si}$. $\mathrm{H}$ atoms are used to passivate the remaining dangling bonds at the surface of the NC. When a Si dangling bond is considered at the $\mathrm{Si} / \mathrm{SiO}_{2}$ interface, one $\mathrm{O}$ atom is removed at the interface. This gives rise to three types of dangling bonds, i.e., $\cdot \mathrm{Si} \equiv\left(\mathrm{SiO}_{2}\right), \cdot \mathrm{Si} \equiv\left(\mathrm{Si}_{2} \mathrm{O}\right)$, and $\cdot \mathrm{Si} \equiv \mathrm{Si}_{3}$ $[33,34,48]$. We have calculated the formation energies of the dangling bonds with these three configurations. It turns out that the formation energies of $\cdot \mathrm{Si} \equiv\left(\mathrm{SiO}_{2}\right), \cdot \mathrm{Si} \equiv\left(\mathrm{Si}_{2} \mathrm{O}\right)$, and $\cdot \mathrm{Si} \equiv \mathrm{Si}_{3}$ are $4.6,2.8$, and $5.7 \mathrm{eV}$, respectively. Since the formation energy of $\cdot \mathrm{Si} \equiv\left(\mathrm{Si}_{2} \mathrm{O}\right)$ is the lowest, the dangling bond is the most likely in the configuration of $\cdot \mathrm{Si} \equiv\left(\mathrm{Si}_{2} \mathrm{O}\right)$. Therefore, we only consider the $\mathrm{Si}$ dangling bond of $\cdot \mathrm{Si} \equiv\left(\mathrm{Si}_{2} \mathrm{O}\right)$ in the current work. Although the thickness of the $\mathrm{SiO}_{2}$ layer at the $\mathrm{NC}$ surface is only $\sim 0.25 \mathrm{~nm}$, the $\mathrm{SiO}_{2}$-induced strain and reduction of the NC band gap are similar to what Seino et al. $[40,49]$ have demonstrated for $\mathrm{Si} \mathrm{NCs}$ embedded in the $\mathrm{SiO}_{2}$ matrax with a rather conplicated model. This indicates the rationality of our models.

A series of substitutional locations of B for the doping of $\mathrm{Si} @ \mathrm{SiO}_{2}$ and $\mathrm{Si} @{ }_{d b} \mathrm{SiO}_{2}$ with $\mathrm{B}$ [Figs. 1(a) and 1(b)] are considered. A substitutional $\mathrm{B}$ atom that moves along the path of $1 \rightarrow 2 \rightarrow 3\left(3^{\prime}\right) \rightarrow 4\left(4^{\prime}\right) \rightarrow 5\left(5^{\prime}\right)$ is denoted as B1, B2, B3 $\left(\mathrm{B}^{\prime}\right), \mathrm{B} 4\left(\mathrm{~B} 4^{\prime}\right)$, or B5 $\left(\mathrm{B}^{\prime}\right)$. When a B atom replaces a Si atom that is originally connected to one, two, or three $\mathrm{H}$ atoms at the surface of $\mathrm{Si} @ \mathrm{SiO}_{2}$ or $\mathrm{Si} @{ }_{d b} \mathrm{SiO}_{2}$, it is denoted as $\mathrm{B}_{a}, \mathrm{~B}_{b}$ or $\mathrm{B}_{c}$, respectively. $\mathrm{B}_{a}, \mathrm{~B}_{b}$, and $\mathrm{B}_{c}$ are passivated by zero, one, and zero $\mathrm{H}$ atoms, respectively. As a $\mathrm{B}$ atom passivates a $\mathrm{Si}$ dangling bond at the $\mathrm{Si} / \mathrm{SiO}_{2}$ interface, it is denoted as $\mathrm{B}_{d b}$.

We have calculated the formation energy $\left(E_{f}\right)$ of a $\mathrm{B}$ atom in $\mathrm{Si} @ \mathrm{SiO}_{2}$ or $\mathrm{Si} @_{d b} \mathrm{SiO}_{2}$ by using $[50,51]$

$$
\begin{aligned}
E_{f}= & E\left(\mathrm{Si}_{x^{\prime}} \mathrm{O}_{y^{\prime}} \mathrm{H}_{z^{\prime}} \mathrm{B}\right)-E\left(\mathrm{Si}_{x} \mathrm{O}_{y} \mathrm{H}_{z}\right)-\mu_{\mathrm{B}}-\left(x^{\prime}-x\right) \mu_{\mathrm{Si}} \\
& -\left(y^{\prime}-y\right) \mu_{\mathrm{O}}-\left(z^{\prime}-z\right) \mu_{\mathrm{H}},
\end{aligned}
$$

where $E\left(\mathrm{Si}_{x} \mathrm{O}_{y} \mathrm{H}_{z}\right)$ and $E\left(\mathrm{Si}_{x^{\prime}} \mathrm{O}_{y^{\prime}} \mathrm{H}_{z^{\prime}} \mathrm{B}\right)$ are the total energy of $\mathrm{Si} @ \mathrm{SiO}_{2}$ or $\mathrm{Si} @ d b \mathrm{SiO}_{2}$ before and after the incorpation of a $\mathrm{B}$ atom, respectively. $x\left(x^{\prime}\right), y\left(y^{\prime}\right)$, and $z\left(z^{\prime}\right)$ are the numbers of $\mathrm{Si}, \mathrm{O}$, and $\mathrm{H}$ atoms, respectively. $\mu_{\mathrm{Si}}, \mu_{\mathrm{O}}, \mu_{\mathrm{H}}$, and $\mu_{\mathrm{B}}$ are the chemical potentials of $\mathrm{Si}, \mathrm{O}, \mathrm{H}$, and $\mathrm{B}$, respectively. The relative order of $E_{f}$ for $\mathrm{B}$ in all kinds of configurations is not affected by the chemical potentials in a rather wide range given the linear relationship between $E_{f}$ and each chemical potential. Thus we obtain the values of $E_{f}$ by choosing $\mu_{\mathrm{Si}}, \mu_{\mathrm{O}}, \mu_{\mathrm{H}}$, and $\mu_{\mathrm{B}}$ to equal the total energies of atomic $\mathrm{Si}$, $\mathrm{O}, \mathrm{H}$, and $\mathrm{B}$ in bulk $\mathrm{Si}$, oxygen gas, hydrogen gas, and $\mathrm{B}_{12}$, respectively [52,53].

Figure 2 shows the values of $E_{f}$ with respect to the location of $\mathrm{B}$ in (a) $\mathrm{Si} @ \mathrm{SiO}_{2}$ or (b) $\mathrm{Si} @{ }_{d b} \mathrm{SiO}_{2}$. It is seen that the values of $E_{f}$ for $\mathrm{B}$ at the $\mathrm{Si} / \mathrm{SiO}_{2}$ interface and the surface of $\mathrm{Si} @ \mathrm{SiO}_{2}$ [i.e., the locations of $4\left(4^{\prime}\right), 5\left(5^{\prime}\right), a$ and $b$ ] are close to those for B in the NC core [Fig. 2(a)]. This result is quite different from that for P-doped $\mathrm{Si} @ \mathrm{SiO}_{2}$, in which a $\mathrm{P}$ atom in the core shows a lower $E_{f}$ compared with that at the $\mathrm{Si} / \mathrm{SiO}_{2}$ interface and the surface of $\mathrm{Si} @ \mathrm{SiO}_{2}$ [38]. Such a difference may be due to the fact that the electronegativity of $\mathrm{B}$ is weaker than that of $\mathrm{P}$. Attractive interaction between $\mathrm{B}$ and $\mathrm{O}$ is larger than that between $\mathrm{P}$ and $\mathrm{O}$. The minimum value of $E_{f}(-5.6 \mathrm{eV})$ appears when B is incorporated as B3' in the subinterface region, indicating that $\mathrm{B}$ is the most likely doped at the subinterface region. This is in contrast to the doping of $\mathrm{Si} @ \mathrm{H}$ with B, where B prefers residing at the surface of Si@H [54].

Figure 2(b) shows the dependence of $E_{f}$ on the location of $\mathrm{B}$ for $\mathrm{Si} @{ }_{d b} \mathrm{SiO}_{2}$. It is noticed that the value of $E_{f}$ for $\mathrm{B} 5$ at the $\mathrm{Si} / \mathrm{SiO}_{2}$ interface is the lowest $(-6.1 \mathrm{eV})$, implying that the $\mathrm{Si} / \mathrm{SiO}_{2}$ interface is more energetically favored for $\mathrm{B}$
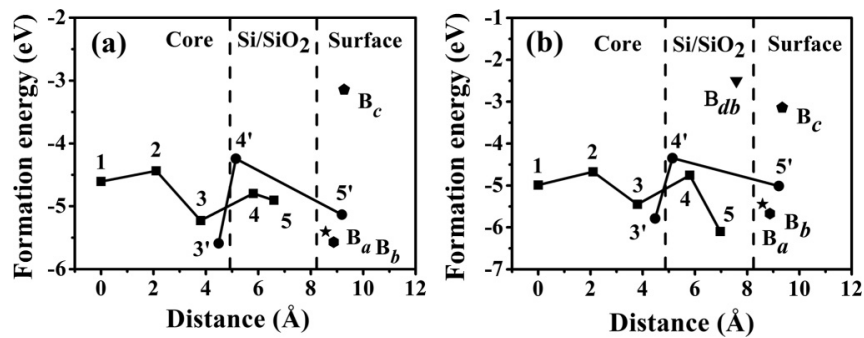

FIG. 2. Formation energy of $\mathrm{B}$ in (a) $\mathrm{Si} @ \mathrm{SiO}_{2}$ or (b) $\mathrm{Si} @{ }_{d b} \mathrm{SiO}_{2}$ as a $\mathrm{B}$ atom substitutionally moves from the center to the surface. The solid lines are used to guide the eye. The vertical dashed lines indicate the regions of the core, $\mathrm{Si} / \mathrm{SiO}_{2}$ interface, and surface. 
when a dangling bond exists at the $\mathrm{Si} / \mathrm{SiO}_{2}$ interface. Since dangling bonds often exist at the $\mathrm{Si} / \mathrm{SiO}_{2}$ interface in the real world [55], our current result predicts that $\mathrm{B}$ may be routinely found to preferentially occupy the $\mathrm{Si} / \mathrm{SiO}_{2}$ interface region when a $\mathrm{Si} \mathrm{NC}$ embedded in $\mathrm{SiO}_{2}$ is doped with B. Khelifi et al. [56] and Xie et al. [57] have recently demonstrated that this is indeed the case. The existence of a dangling bond at the $\mathrm{Si} / \mathrm{SiO}_{2}$ interface also reduces the values of $E_{f}$ for $\mathrm{B}$ in the NC core [Fig. 2(b)], which means that defects such as Si dangling bonds at the $\mathrm{Si} / \mathrm{SiO}_{2}$ interface may facilitate the incorporation of $\mathrm{B}$ for $\mathrm{Si} \mathrm{NCs}$ embedded in $\mathrm{SiO}_{2}$. In contrast to P-doped $\mathrm{Si} @{ }_{d b} \mathrm{SiO}_{2}$ [38], B is the least likely to passivate dangling bonds in $\mathrm{Si} @ d b \mathrm{SiO}_{2}$. This is consistent with Fujio et al.'s [55] experimental work on B-doped Si NCs embedded in $\mathrm{SiO}_{2}$. They showed that the electron spin resonance (ESR) signal of dangling bonds remains after $\mathrm{Si} \mathrm{NCs}$ are doped with B.

\section{B. Electronic structure}

Figure 3 shows the energy-level diagrams for undoped and B-doped (a) $\mathrm{Si} @ \mathrm{SiO}_{2}$ or (b) $\mathrm{Si} @ d b \mathrm{SiO}_{2}$. For $\mathrm{Si} @ \mathrm{SiO}_{2}$, deep energy levels are introduced in the band gap when $\mathrm{B}$ is in the configurations of $\mathrm{B} 1, \mathrm{~B} 2, \mathrm{~B} 3\left(\mathrm{~B} 3^{\prime}\right), \mathrm{B} 4\left(\mathrm{~B} 4^{\prime}\right)$, and $\mathrm{B} 5\left(\mathrm{~B}^{\prime}\right)$. This is mainly due to the B-doping-induced odd
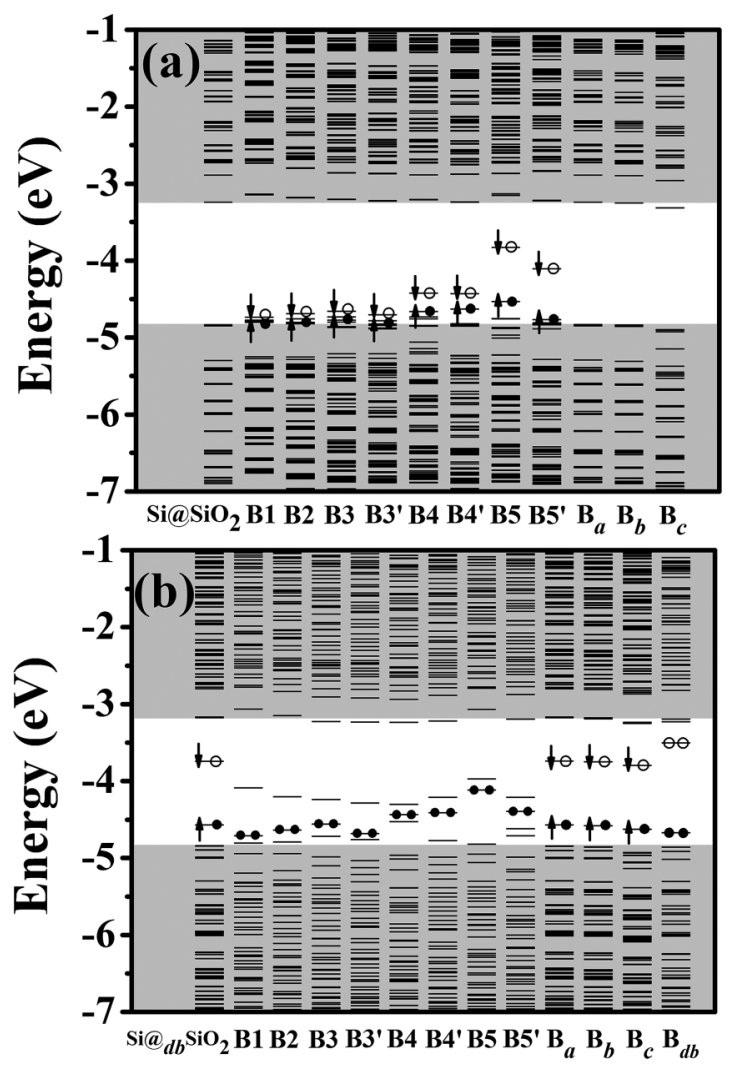

FIG. 3. Energy-level diagrams for undoped and B-doped (a) $\mathrm{Si} @ \mathrm{SiO}_{2}$ or (b) $\mathrm{Si} @_{d b} \mathrm{SiO}_{2}$ at the ground state. Filled (empty) circles indicate that energy levels are occupied (unoccupied) by electrons. Spin-up (spin-down) states of defect energy levels induced by a B atom or dangling bond are indicated by up (down) arrows. number of electrons in a NC. Among these configurations, the B-doping-induced deep energy levels of B1, B2, B3, and $\mathrm{B}^{\prime}$ are close to the valence band with a small spin splitting, while those of B4, B4', B5, and B5' are deep with a large spin splitting. The spin splitting of the deep energy level is associated with the polarizability of bonds, which is determined by the variation of the bond length. For B-doped $\mathrm{Si} @ \mathrm{SiO}_{2}$ with the configurations of B1, B2, B3, and B3', the bond lengths of four Si-B bonds are almost identical with each other, giving rise to rather small polarization of the bonds. In these cases, the electron density of the HODE and LUDE are mainly located at the $\mathrm{B}$ and neighboring $\mathrm{Si}$ atoms with similar distributions [representatively shown for $\mathrm{Si} @ \mathrm{SiO}_{2}$ doped with B3' in Fig. 4(a)]. However, there are significant changes of bond length when $\mathrm{B}$ is doped in the configurations of $\mathrm{B} 4$, B4', B5, and B5'. For example, for B-doped $\mathrm{Si} @ \mathrm{SiO}_{2}$ with the configuration of $\mathrm{B} 5$, the bond length of a $\mathrm{Si}-\mathrm{B}$ bond is stretched by $60 \%$ and that of the adjacent $\mathrm{Si}-\mathrm{B}$ bond is compressed by $10 \%$. For B5'-doped $\mathrm{Si} @ \mathrm{SiO}_{2}$, the B atom even moves to the NC surface after structural optimization [Fig. 1(a)], creating a $\mathrm{Si}$ dangling bond at the $\mathrm{Si} / \mathrm{SiO}_{2}$ interface. In these cases, the electron density of the HODE and LUDE are mainly localized at the $\mathrm{B}$ atom and adjacent Si dangling bond with divergent distributions [representatively shown for $\mathrm{Si} @ \mathrm{SiO}_{2}$ doped with B5 in Fig. 4(a)]. It is the strong localization and divergent distribution of the electron density of HODE and LUDE that contributes to the deep energy levels and large spin splitting, respectively.

The band gap of undoped $\mathrm{Si} @ \mathrm{SiO}_{2}$ is slightly enlarged when a dangling bond exists at the $\mathrm{Si} / \mathrm{SiO}_{2}$ interface $(1.59 \rightarrow$ $1.66 \mathrm{eV})$. In the meantime, the dangling bond introduces deep energy levels in the band gap, which is evidenced by the fact that the electron density of the HODE and LUDE of $\mathrm{Si} @_{d b} \mathrm{SiO}_{2}$ are mainly localized at the dangling bond [Fig. 4(b)]. For $\mathrm{Si} @{ }_{d b} \mathrm{SiO}_{2}$ doped with B in the configurations of $\mathrm{B} 1, \mathrm{~B} 2, \mathrm{~B} 3\left(\mathrm{~B} 3^{\prime}\right), \mathrm{B} 4\left(\mathrm{~B} 4^{\prime}\right)$, and $\mathrm{B} 5\left(\mathrm{~B} 5^{\prime}\right)$, deep energy levels remain. Similar to what happens to $\mathrm{Si} @ \mathrm{SiO}_{2}$, the bond length is almost unchanged when $\mathrm{B}$ is doped in the configurations of B1, B2, B3, and B3'. The electron density of the HODE are localized around B, while those of the LUDE are localized on the dangling bond [representatively shown for $\mathrm{Si} @_{d b} \mathrm{SiO}_{2}$ doped with B3' in Fig. 4(b)]. We find that the single electron of the original dangling bond is transferred to form an electron pair together with that of a B atom. The electron pair occupies the HODE with opposite spins, consistent with Pauli's exclusion principle. For the configurations of B4, B4', B5, and B5', significant changes of bond length appear. Both the electron density of the HODE and LUDE are localized on the dangling bond and the $\mathrm{Si}$ atom with the largest bond length, leading to deeper energy levels in the band gaps of these configurations. In contrast to P-doped $\mathrm{Si} @{ }_{d b} \mathrm{SiO}_{2}$ with the configuration of $\mathrm{P}_{d b}$ [38], $\mathrm{B}$ doping does not eliminate the deep energy levels with the configuration of $\mathrm{B}_{d b}$ [Fig. 3(b)]. The electron density of the HODE and LUDE are mainly localized on $\mathrm{B}_{d b}$ [Fig. 4(b)]. The incorporation of $\mathrm{B}_{a}, \mathrm{~B}_{b}$, or $\mathrm{B}_{c}$ hardly changes the energy-level scheme and electron density of the HOMO and LUMO for $\mathrm{Si} @ \mathrm{SiO}_{2}$ or $\mathrm{Si} @{ }_{d b} \mathrm{SiO}_{2}$ (Figs. 3 and 4) because $\mathrm{B}_{a}, \mathrm{~B}_{b}$, or $\mathrm{B}_{c}$ is in threefold coordination at the surface without introducing a single electron. 
(a)
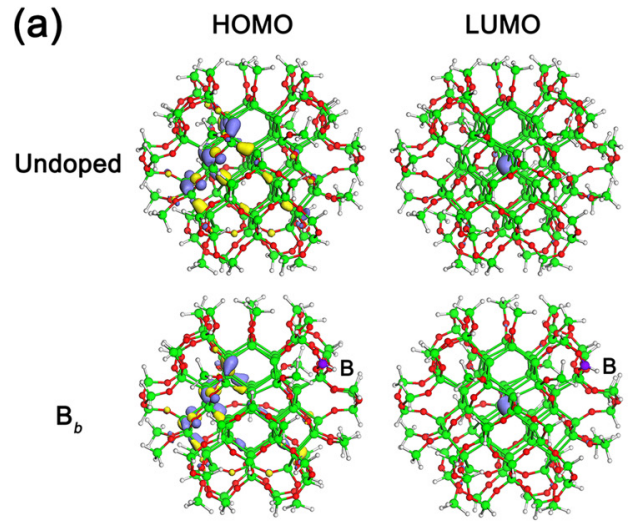

HODE
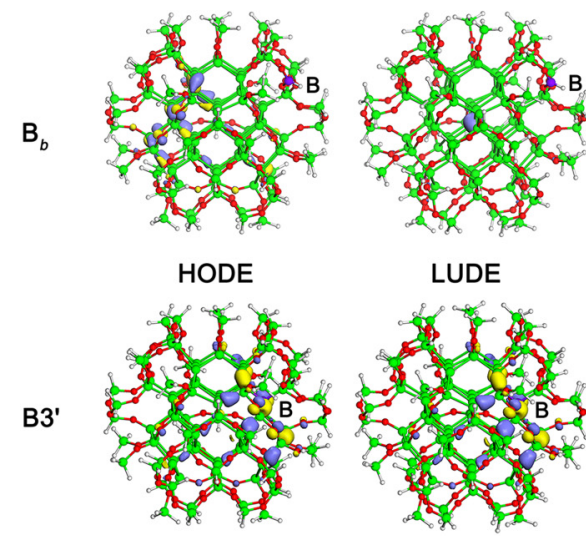

LUDE

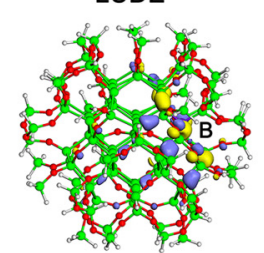

B5
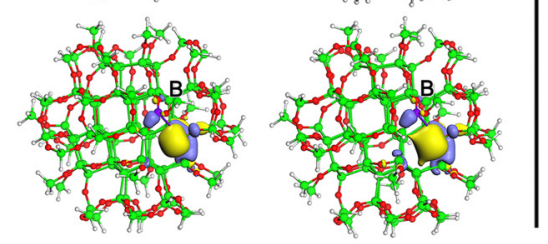
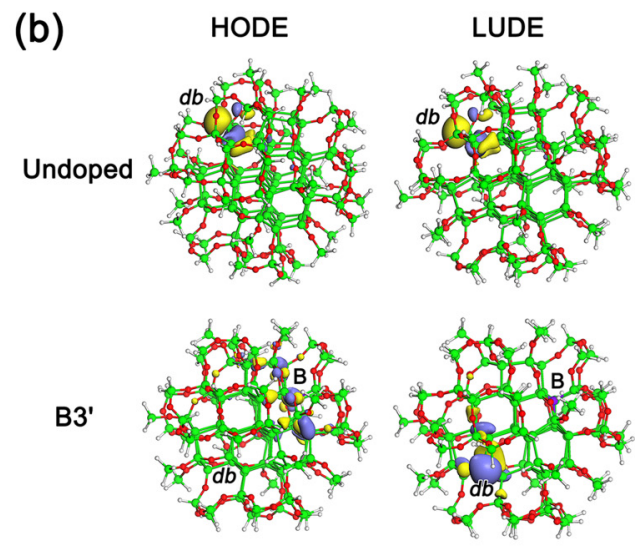

B5
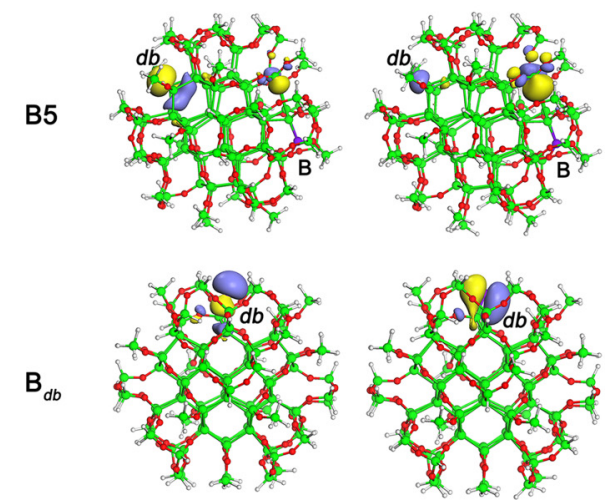

FIG. 4. (a) Distribution of the isosurface for the electron density of the highest occupied molecular orbital (HOMO) and lowest unoccupied molecular orbital (LUMO) for undoped or $\mathrm{B}_{b}$-doped $\mathrm{Si} @ \mathrm{SiO}_{2}$. Those of the highest occupied deep energy-level (HODE) and the lowest unoccupied deep energy-level (LUDE) for B3'- or B5-doped $\mathrm{Si} @ \mathrm{SiO}_{2}$ are also shown. (b) Distribution of the isosurface for the electron density of the HODE and LUDE for undoped, B3'-, B5-, or $\mathrm{B}_{d b}$-doped $\mathrm{Si}_{d b} \mathrm{SiO}_{2}$.

\section{B/P CODOPING}

\section{A. Formation energy}

Now we focus on the synergic effect of $\mathrm{B} / \mathrm{P}$ codoping for $\mathrm{Si} \mathrm{NCs}$ embedded in $\mathrm{SiO}_{2}$. For $\mathrm{Si} @ \mathrm{SiO}_{2}$, the configurations in which $\mathrm{B}$ and $\mathrm{P}$ are both incorporated in their energetically favored locations of $3\left(3^{\prime}\right)$ at the subinterface region of the $\mathrm{NC}$ are first considered [38]. For these configurations, the dopants can either be located separately (denoted as P3-B3') or form a $\mathrm{B}-\mathrm{P}$ pair (denoted as $\left\{\mathrm{P} 3-\mathrm{B} 3^{\prime}\right\}$ or $\left\{\mathrm{P}^{\prime}-\mathrm{B} 3\right\}$ ). In order to figure out which atom is more likely to be incorporated into the core region of the $\mathrm{NC}$ when it is codoped with $\mathrm{B}$ and $\mathrm{P}$, the configuration of $\mathrm{P} 1-\mathrm{B} 3^{\prime}$ or $\mathrm{P}^{\prime}$ '- $\mathrm{B} 1$ with a $\mathrm{P}$ or $\mathrm{B}$ atom in the center of the NC is representatively considered. For $\mathrm{Si} @{ }_{d b} \mathrm{SiO}_{2}$, given the result that $\mathrm{P}$ is the most likely to passivate the dangling bond at the $\mathrm{Si} / \mathrm{SiO}_{2}$ interface [38]. the dangling bond is first passivated by a $\mathrm{P}$ atom. A substitutional $\mathrm{B}$ atom moving along the path of $1 \rightarrow 2 \rightarrow 3 \rightarrow 4 \rightarrow 5$ is considered. To avoid any strong interaction between the dopants, the path is chosen to be far from $\mathrm{P}_{d b}$. These configurations are denoted as $\mathrm{P}_{d b}-\mathrm{B} 1, \mathrm{P}_{d b}-\mathrm{B} 2, \mathrm{P}_{d b}-\mathrm{B} 3, \mathrm{P}_{d b}-\mathrm{B} 4$, and $\mathrm{P}_{d b}-\mathrm{B} 5$. Moreover, a $\mathrm{B}-\mathrm{P}$ pair in the configuration of $\left\{\mathrm{P}_{d b}-\mathrm{B} 4^{\prime}\right\}$ is considered to investigate the interaction between the dopants for $\mathrm{Si} @{ }_{d b} \mathrm{SiO}_{2}$. Figure 5 shows the models of (a) P3-B3' codoped $\mathrm{Si} @ \mathrm{SiO}_{2}$ and (b) $\mathrm{P}_{d b}$-B5 codoped $\mathrm{Si} @ d b \mathrm{SiO}_{2}$.
The $E_{f}$ of the dopants in $\mathrm{Si} @ \mathrm{SiO}_{2}$ or $\mathrm{Si} @{ }_{d b} \mathrm{SiO}_{2}$ is calculated by using

$$
\begin{aligned}
E_{f}= & E\left(\mathrm{Si}_{x^{\prime}} \mathrm{O}_{y^{\prime}} \mathrm{H}_{z^{\prime}} \mathrm{BP}\right)-E\left(\mathrm{Si}_{x} \mathrm{O}_{y} \mathrm{H}_{z}\right)-\mu_{\mathrm{B}}-\mu_{\mathrm{P}} \\
& -\left(x^{\prime}-x\right) \mu_{\mathrm{Si}}-\left(y^{\prime}-y\right) \mu_{\mathrm{O}}-\left(z^{\prime}-z\right) \mu_{\mathrm{H}} .
\end{aligned}
$$

$E\left(\mathrm{Si}_{x} \mathrm{O}_{y} \mathrm{H}_{z}\right)$ and $E\left(\mathrm{Si}_{x^{\prime}} \mathrm{O}_{y^{\prime}} \mathrm{H}_{z^{\prime}} \mathrm{BP}\right)$ are the total energy of $\mathrm{Si} @ \mathrm{SiO}_{2}$ or $\mathrm{Si} @{ }_{d b} \mathrm{SiO}_{2}$ before and after the incorpation of $\mathrm{B} / \mathrm{P}$ dopants, respectively. $x\left(x^{\prime}\right), y\left(y^{\prime}\right)$, and $z\left(z^{\prime}\right)$ are the numbers of $\mathrm{Si}, \mathrm{O}$, and $\mathrm{H}$ atoms, respectively. $\mu_{\mathrm{P}}$ is the chemical potential
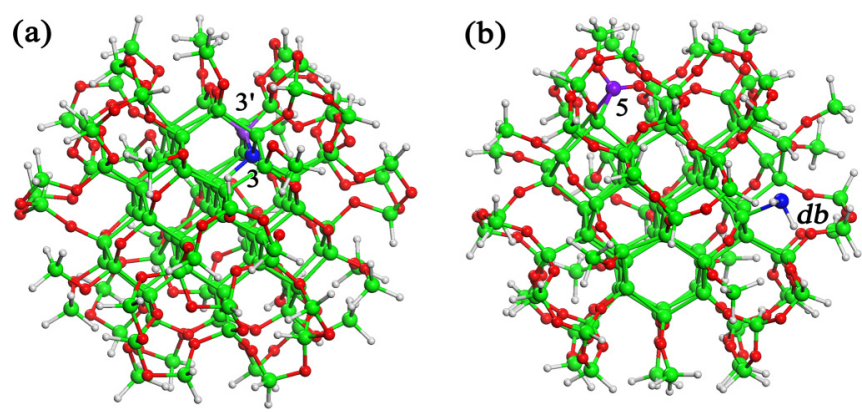

FIG. 5. Model of a (a) $\mathrm{Si} @ \mathrm{SiO}_{2}$ codoped with $\mathrm{P} 3$ and B3' or (b) $\mathrm{Si} @_{d b} \mathrm{SiO}_{2}$ codoped with $\mathrm{P}_{d b}$ and $\mathrm{B} 5 . \mathrm{Si}, \mathrm{H}, \mathrm{O}, \mathrm{B}$, and $\mathrm{P}$ atoms are denoted by green, gray, red, violet, and blue balls, respectively. 

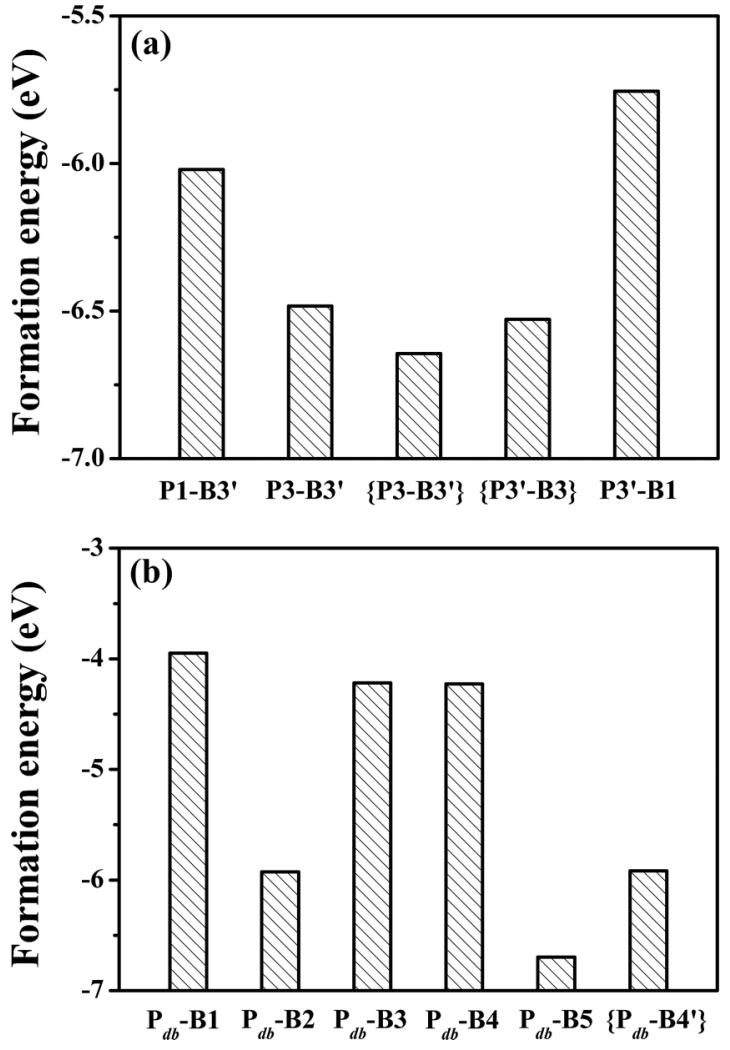

FIG. 6. Formation energies of $\mathrm{B} / \mathrm{P}$ dopants in (a) $\mathrm{Si}_{\mathrm{SiO}}$ or (b) $\mathrm{Si} @{ }_{d b} \mathrm{SiO}_{2}$.

of $\mathrm{P}$, which equals the total energy of atomic $\mathrm{P}$ in orthorhombic black phosphorus [39].

Figure 6 shows the dependence of $E_{f}$ on the locations of B/P dopants for (a) $\mathrm{Si} @ \mathrm{SiO}_{2}$ or (b) $\mathrm{Si} @ d b \mathrm{SiO}_{2}$. For $\mathrm{Si} @ \mathrm{SiO}_{2}$, it is clear that the value of $E_{f}$ for $\mathrm{P} 3-\mathrm{B}^{\prime},\left\{\mathrm{P} 3-\mathrm{B} 3^{\prime}\right\}$, or $\left\{\mathrm{P}^{\prime}-\right.$ $\mathrm{B} 3\}$ is smaller than that for $\mathrm{P} 1-\mathrm{B}^{\prime}$ or $\mathrm{P} 3^{\prime}-\mathrm{B} 1$ [Fig. 6(a)], indicating that it is more energetically stable when both $\mathrm{B}$ and $\mathrm{P}$ are incorporated at the subinterface of the $\mathrm{NC}$. The value of $E_{f}$ is further reduced when B and $\mathrm{P}$ atoms are doped in the form of a B-P pair. Interestingly, we find that the value of $E_{f}$ for $\mathrm{B} / \mathrm{P}$ in the configuration of $\left\{\mathrm{P} 3-\mathrm{B} 3^{\prime}\right\}$ is smaller than that in the configuration of $\left\{\mathrm{P}^{\prime}-\mathrm{B} 3\right\}$ (-6.64 vs $\left.-6.53 \mathrm{eV}\right)$. This is mainly because the position of $3^{\prime}$ is closer to the $\mathrm{SiO}_{2}$ layer than that of 3. A larger attractive interaction between $\mathrm{B}$ and electronegative oxygen atoms makes B more energetically favored towards the $\mathrm{SiO}_{2}$ layer than $\mathrm{P}$. Therefore, the configuration of $\left\{\mathrm{P} 3-\mathrm{B}^{\prime}\right\}$ is more likely to be formed compared to that of $\left\{\mathrm{P}^{\prime}-\mathrm{B} 3\right\}$. The existence of a dangling bond makes a difference for the distribution of $\mathrm{B}$ and $\mathrm{P}$ in $\mathrm{Si} @_{d b} \mathrm{SiO}_{2}$. For $\mathrm{Si} @_{d b} \mathrm{SiO}_{2}$, the lowest value of $E_{f}$ occurs in the configuration of $\mathrm{P}_{d b}-\mathrm{B} 5$, rather than $\left\{\mathrm{P}_{d b}-\mathrm{B} 4^{\prime}\right\}$ [Fig. 6(b)]. This means that $\mathrm{B}$ and $\mathrm{P}$ are more likely incorporated at the $\mathrm{Si} / \mathrm{SiO}_{2}$ interface of $\mathrm{Si} @{ }_{d b} \mathrm{SiO}_{2}$ but not in the form of a B-P pair. For both $\mathrm{Si} @ \mathrm{SiO}_{2}$ and $\mathrm{Si} @{ }_{d b} \mathrm{SiO}_{2}, \mathrm{~B}$ is not likely incorporated in the center of the $\mathrm{NCs}$ during the codoping of $\mathrm{B}$ and $\mathrm{P}$, given the highest values of $E_{f}$ for the configurations of P3'-B1 and $\mathrm{P}_{d b}-\mathrm{B} 1$ in $\mathrm{Si} @ \mathrm{SiO}_{2}$ and $\mathrm{Si} @ d b \mathrm{SiO}_{2}$, respectively.
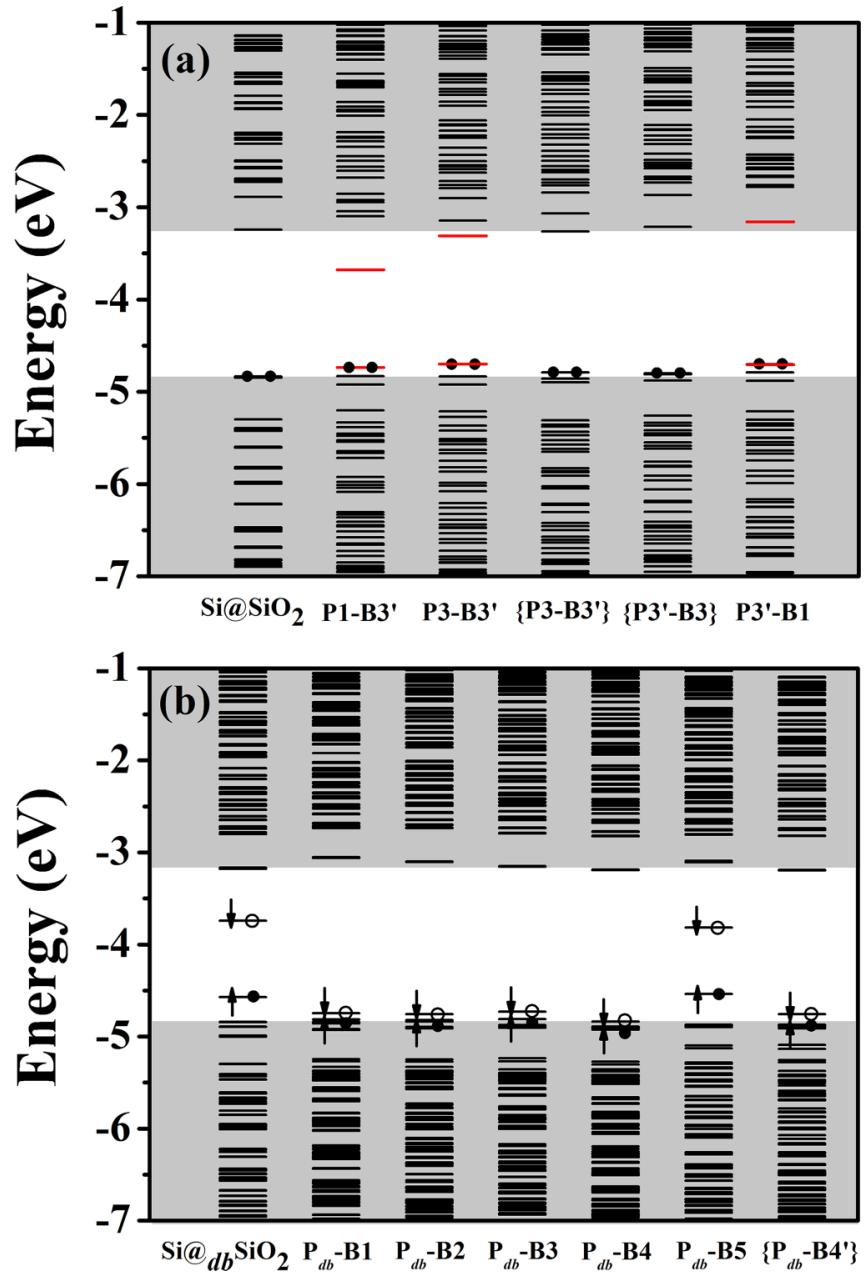

FIG. 7. Energy-level diagrams for undoped and B/P-codoped (a) $\mathrm{Si} @ \mathrm{SiO}_{2}$ or (b) $\mathrm{Si} @{ }_{d b} \mathrm{SiO}_{2}$ at the ground state. Filled (empty) circles indicate that energy levels are occupied (unoccupied) by electrons. Spin-up (spin-down) states of defect energy levels are indicated by up (down) arrows. The highest occupied deep energy-level (HODE) and lowest unoccupied deep energy-level (LUDE) are indicated by red bars.

\section{B. Electronic structure}

The energy-level diagrams for undoped and B/P-codoped $\mathrm{Si} @ \mathrm{SiO}_{2}$ or $\mathrm{Si} @ d b \mathrm{SiO}_{2}$ are shown in Fig. 7. For $\mathrm{Si} @ \mathrm{SiO}_{2}$, deep energy levels are introduced in the band gap when $\mathrm{B}$ and $\mathrm{P}$ are in the configurations of $\mathrm{P} 1-\mathrm{B}^{\prime}, \mathrm{P} 3-\mathrm{B} 3^{\prime}$, and $\mathrm{P} 3^{\prime}-\mathrm{B} 1$. The electron density of HODE and LUDE are mainly localized at $\mathrm{B}$ and $\mathrm{P}$, respectively. This is representatively shown for $\mathrm{Si} @ \mathrm{SiO}_{2}$ codoped with P1-B3' or P3-B3' in Fig. 8(a). Figure 9 shows the HODE-LUDE, LUDE-LUMO, and HODE-HOMO gaps for $\mathrm{B} / \mathrm{P}$-codoped $\mathrm{Si} @ \mathrm{SiO}_{2}$ with the configuration of $\mathrm{P} 1-\mathrm{B} 3^{\prime}, \mathrm{P} 3-\mathrm{B} 3^{\prime}$, or $\mathrm{P}^{\prime}-\mathrm{B} 1$. It is seen that the band gap between the deep energy levels (HODE-LUDE gap) varies from 1.0 to $1.5 \mathrm{eV}$ for $\mathrm{B} / \mathrm{P}$-codoped $\mathrm{Si} @ \mathrm{SiO}_{2}$ within these configurations. The LUDE-LUMO gap is much larger than the HODE-HOMO gap for the configurations of P1-B3' and P3'-B1, while they are almost identical with each other for the configuration of $\mathrm{P} 3-\mathrm{B} 3{ }^{\prime}$. This demonstrates that the depth of $\mathrm{B} / \mathrm{P}$-codoping-induced energy levels is affected by the relative 
(a)

P1-B3'
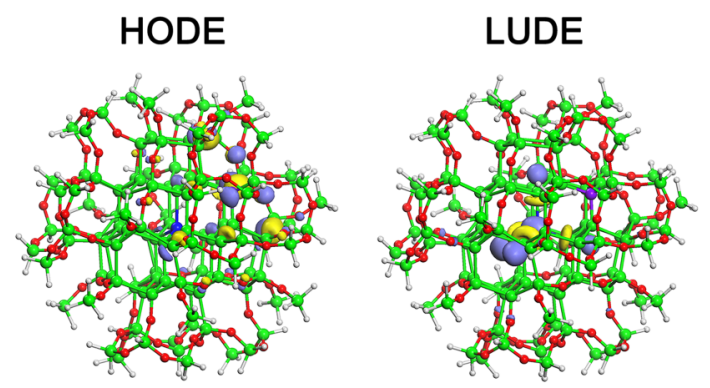

P3-B3'

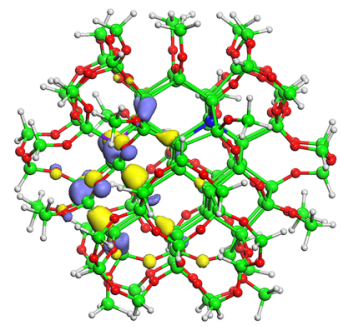

HOMO

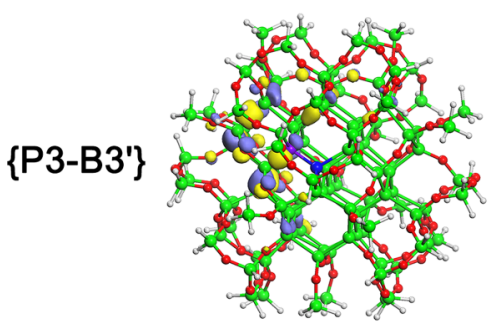

(b)

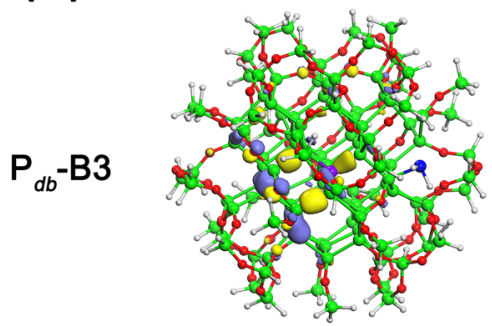

HODE
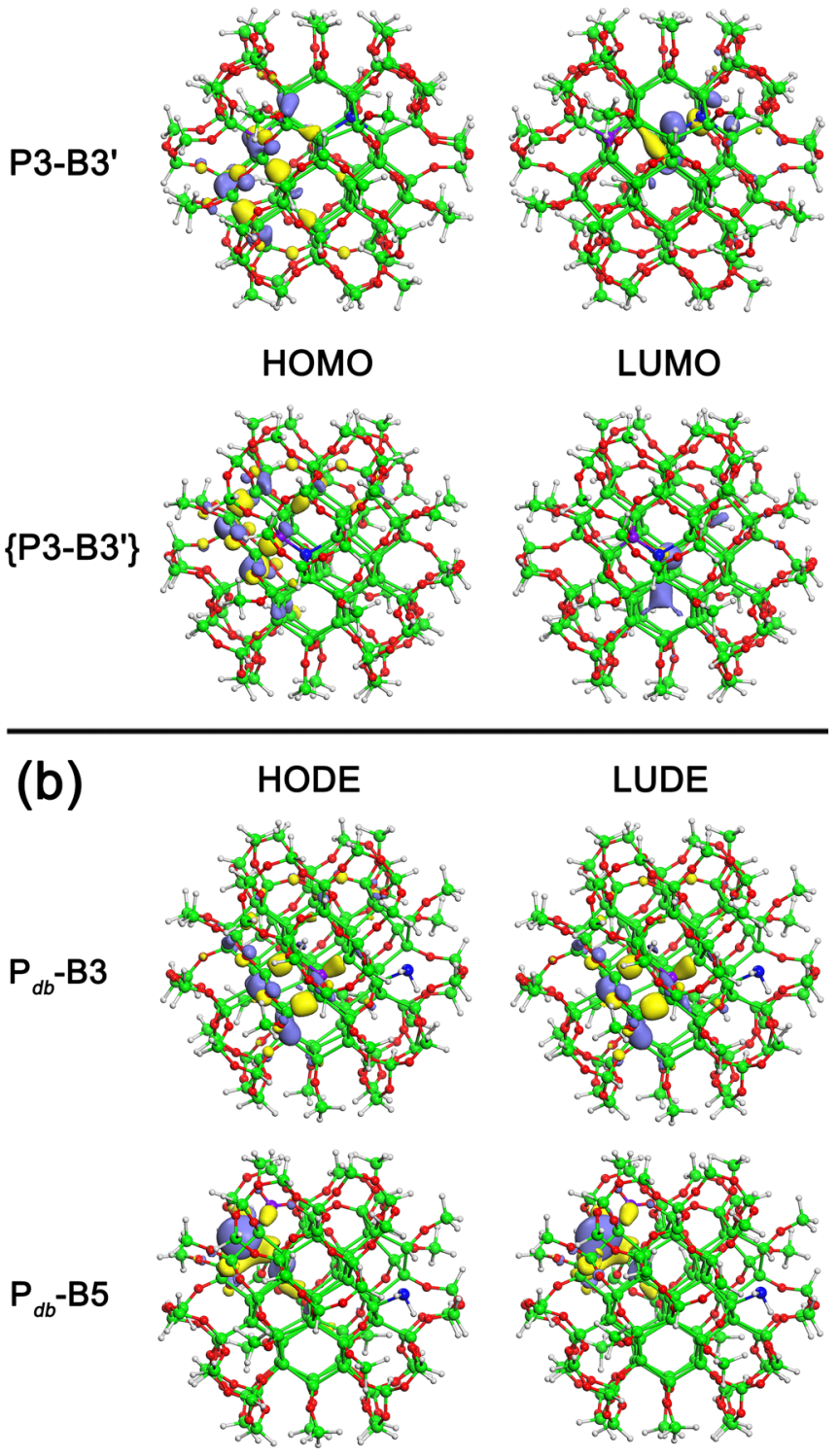

LUMO

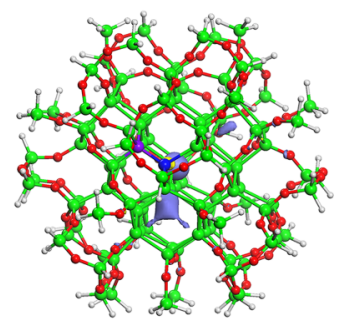

LUDE
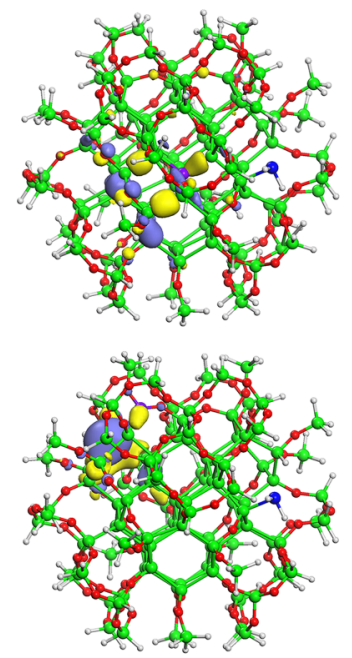

FIG. 8. (a) Distribution of isosurface for the electron density of the HODE and LUDE for P1-B3' or P3-B3' codoped $\mathrm{Si} @ \mathrm{SiO}_{2}$. Those of the HOMO and LUMO for $\left\{\mathrm{P} 3-\mathrm{B}^{\prime}\right\}$ codoped $\mathrm{Si} @ \mathrm{SiO}_{2}$ are also shown. (b) Distribution of the isosurface for the electron density of the HODE and LUDE for $\mathrm{P}_{d b}-\mathrm{B} 3$ or $\mathrm{P}_{d b}-\mathrm{B} 5$ codoped $\mathrm{Si} @{ }_{d b} \mathrm{SiO}_{2}$.

positions of $\mathrm{B}$ and $\mathrm{P}$ atoms in the NC. Recently, Nakamura et al. [31] observed multiphotoluminescence (PL) peaks in heavily $\mathrm{B} / \mathrm{P}$-codoped $\mathrm{Si} \mathrm{NCs}$ embedded in $\mathrm{SiO}_{2}$. The PL energy of one of the peaks depends on the dopant concentration. These experimental results can be well explained by our

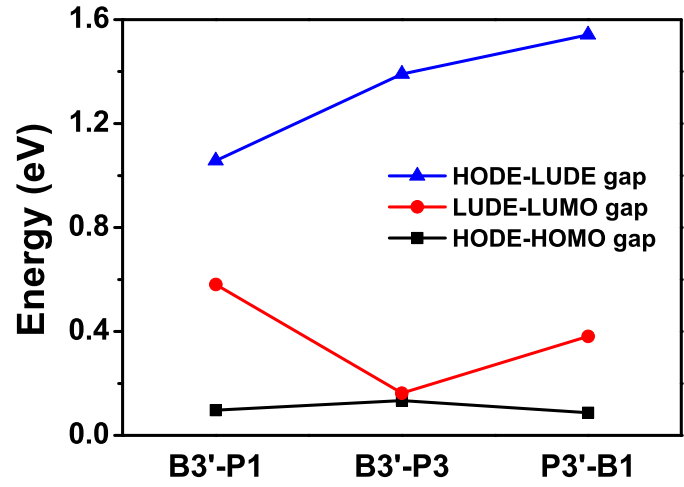

FIG. 9. HODE-LUDE, LUDE-LUMO, and HODE-HOMO gaps for $\mathrm{P} 1-\mathrm{B} 3$ ', $\mathrm{P} 3-\mathrm{B} 3$ ', or $\mathrm{P} 3^{\prime}-\mathrm{B} 1$ codoped $\mathrm{Si} @ \mathrm{SiO}_{2}$. The solid line is used to guide the eye.

current finding that $\mathrm{B} / \mathrm{P}$ codoping leads to localized states with different depths in the band gap, which are responsible for different $\mathrm{PL}$ energies. When $\mathrm{B}$ and $\mathrm{P}$ atoms are codoped in the form of B-P pairs (i.e., $\left\{\mathrm{P} 3-\mathrm{B} 3^{\prime}\right\}$ and $\left.\left\{\mathrm{P}^{\prime}-\mathrm{B} 3\right\}\right)$, no deep energy levels are introduced in the band gap. The electron density of the HOMO and LUMO are basically delocalized among $\mathrm{Si}$ atoms [representatively shown for $\mathrm{Si} @ \mathrm{SiO}_{2}$ codoped with $\left\{\mathrm{P} 3-\mathrm{B}^{\prime}\right\}$ in Fig. 8(a)].

For $\mathrm{Si} @_{d b} \mathrm{SiO}_{2}$, when a $\mathrm{P}$ atom passivates the dangling bond with the configuration of $\mathrm{P}_{d b}$, the energy-level scheme of the NC becomes akin to that of undoped $\mathrm{Si} @ \mathrm{SiO}_{2}$ [38]. Similar to what happens to $\mathrm{Si} @ \mathrm{SiO}_{2}$, the incorporation of an additional $\mathrm{B}$ atom in the configurations of B1, B2, B3, B4, B4', and B5 introduces deep energy levels in the band gap of $\mathrm{Si} @{ }_{d b} \mathrm{SiO}_{2}$. For B/P-codoped $\mathrm{Si} @_{d b} \mathrm{SiO}_{2}$ with the configurations of $\mathrm{P}_{d b}-\mathrm{B} 1, \mathrm{P}_{d b}-\mathrm{B} 2, \mathrm{P}_{d b}-\mathrm{B} 3, \mathrm{P}_{d b}-\mathrm{B} 4$, and $\left\{\mathrm{P}_{d b}-\mathrm{B} 4{ }^{\prime}\right\}$, the electron density of the HODE and LUDE are mainly localized at the $\mathrm{B}$ atom [representatively shown for $\mathrm{Si} @_{d b} \mathrm{SiO}_{2}$ codoped with $\mathrm{P}_{d b}$-B3 in Fig. 8(b)]. For $\mathrm{P}_{d b}$-B5 codoped $\mathrm{Si} @_{d b} \mathrm{SiO}_{2}$, significant changes of bond length appear. The electron density of the HODE and LUDE are mainly localized at the B and Si atoms with the largest structural distortion [Fig. 8(b)].

\section{CONCLUSIONS}

We have studied the $\mathrm{B}$ doping and $\mathrm{B} / \mathrm{P}$ codoping of a $\mathrm{Si} \mathrm{NC}$ embedded in $\mathrm{SiO}_{2}$ with a perfect $\mathrm{Si} / \mathrm{SiO}_{2}$ interface $\left(\mathrm{Si} @ \mathrm{SiO}_{2}\right)$ or defective $\mathrm{Si} / \mathrm{SiO}_{2}$ interface $\left(\mathrm{Si} @{ }_{d b} \mathrm{SiO}_{2}\right)$. The current results show that $\mathrm{B}$ is most likely incorporated into the subinterface of $\mathrm{Si} @ \mathrm{SiO}_{2}$. However, the existence of a dangling bond at the $\mathrm{Si} / \mathrm{SiO}_{2}$ interface makes $\mathrm{B}$ more energetically prefer the $\mathrm{Si} / \mathrm{SiO}_{2}$ interface. In contrast to the doping of $\mathrm{Si} @{ }_{d b} \mathrm{SiO}_{2}$ with $\mathrm{P}, \mathrm{B}$ is not likely to passivate the dangling bond.

For B/P-codoped $\mathrm{Si}_{0} \mathrm{SiO}_{2}$, a B atom and a P atom tend to be bonded as a B-P pair at the subinterface of the NC. A larger electronic attractive interaction between $\mathrm{B}$ and $\mathrm{O}$ atoms makes $\mathrm{B}$ atoms more energetically prefer positions close to the $\mathrm{SiO}_{2}$ layer. As a consequence, a static electric dipole that radially points toward the $\mathrm{NC}$ core is formed at the subinterface region. In fact, B or P may enter the NC core when they are heavily doped. In this case, deep energy levels are introduced in the band gap of $\mathrm{Si} @ \mathrm{SiO}_{2}$. The HODE-LUDE gap is affected by the relative positions of $\mathrm{B}$ and $\mathrm{P}$ atoms. 
Finally, we would like to comment on the dependence of the properties of B-doped and B/P-codoped Si NCs embedded in $\mathrm{SiO}_{2}$ on the NC size. As previously demonstrated for P-doped $\mathrm{Si}$ NCs embedded in $\mathrm{SiO}_{2}$ [38], the trend of the variation of $E_{f}$ with respect to the dopant atom position may not change despite the change of the specific value of $E_{f}$ when the NC size varies. Therefore, the similar preferential distribution of $\mathrm{B}$ and codoped $\mathrm{B} / \mathrm{P}$ should occur as the $\mathrm{NC}$ size changes from $1.4 \mathrm{~nm}$ to a different one. It has been shown that the electronic structures of doped Si NCs critically depend on the doping-induced structural distortion [38,47]. When the NC size is $\geqslant 1.4 \mathrm{~nm}$, Si NCs are less vulnerable to structural distortion [58-60]. Therefore, the current findings for the electronic structures of 1.4-nm B-doped and B/P-codoped Si NCs may be well qualitatively applied to larger Si NCs. It is clear that dedicated DFT studies are highly desired to quantitatively show the size effect for all kinds of doped
Si NCs. With the continuous development of calculation methods and capacities this should be realized in the future. For now, current insights gained on the 1.4-nm B-doped and B/P-codoped Si NCs embedded in $\mathrm{SiO}_{2}$ may encourage both theorists and experimentalists to further explore the great potential of Si NCs through controllable doping.

\section{ACKNOWLEDGMENTS}

Shanghai Supercomputer Center is acknowledged for providing computation resources. This study is mainly supported by the National Basic Research Program of China (Grant No. 2013CB632101), the Natural Science Foundation of China (NSFC) for Excellent Young Researchers program (Grant No. 61222404), and the NSFC-FWO program (Grants No. 61411130229 and No. 61511130264$)$.
[1] T. Yu, F. Wang, Y. Xu, L. L. Ma, X. D. Pi, and D. Yang, Adv. Mater. 28, 4912 (2016).

[2] R. J. Walters, G. I. Bourianoff, and H. A. Atwater, Nat. Mater. 4, 143 (2005).

[3] F. Maier-Flaig, J. Rinck, M. Stephan, T. Bocksrocker, M. Bruns, C. Kubel, A. K. Powell, G. A. Ozin, and U. Lemmer, Nano Lett. 13, 475 (2013).

[4] D. P. Puzzo, E. J. Henderson, M. G. Helander, Z. Wang, G. A. Ozin, and Z. Lu, Nano Lett. 11, 1585 (2011).

[5] K. Y. Cheng, R. Anthony, U. R. Kortshagen, and R. J. Holmes, Nano Lett. 11, 1952 (2011).

[6] L. Yao, T. Yu, L. X. Ba, H. Meng, X. Fang, Y. L. Wang, L. Li, X. Rong, S. Wang, X. Q. Wang, G. Z. Ran, X. D. Pi, and G. G. Qin, J. Mater. Chem. C 4, 673 (2016).

[7] S. Y. Zhao, X. D. Pi, C. Mercier, Z. C. Yuan, B. Q. Sun, and D. Yang, Nano Energy 26, 305 (2016).

[8] C.-Y. Liu, Z. C. Holman, and U. R. Kortshagen, Adv. Funct. Mater. 20, 2157 (2010).

[9] Y. Ding, M. Sugaya, Q. Liu, S. Zhou, and T. Nozaki, Nano Energy 10, 322 (2014)

[10] X. D. Pi, L. Zhang, and D. Yang, J. Phys. Chem. C 116, 21240 (2012).

[11] J. Xu, S. H. Sun, Y. Q. Cao, P. Lu, W. Li, and K. J. Chen, Part. Part. Syst. Charact. 31, 459 (2014).

[12] N. Liu, Z. Lu, J. Zhao, M. T. McDowell, H.-W. Lee, W. Zhao, and Y. Cui, Nat. Nanotechnol. 9, 187 (2014).

[13] L. Zhong, J. Guo, and L. Mangolini, J. Power Sources 273, 638 (2015).

[14] X. Cheng, S. B. Lowe, P. J. Reece, and J. J. Gooding, Chem. Soc. Rev. 43, 2680 (2014).

[15] Y. L. Zhong, X. T. Sun, S. Y. Wang, F. Peng, F. Bao, Y. Y. Su, Y. Y. Li, S.-T. Lee, and Y. He, ACS Nano 9, 5958 (2015).

[16] S. Park, E. Cho, D. Song, G. Conibeer, and M. A. Green, Sol. Energy Mater. Sol. Cells 93, 684 (2009).

[17] A. R. Stegner, R. N. Pereira, K. Klein, R. Lechner, R. Dietmueller, M. S. Brandt, M. Stutzmann, and H. Wiggers, Phys. Rev. Lett. 100, 026803 (2008).

[18] M. Kummer, J. P. Badillo, A. Schmitz, H. G. Bremes, M. Winter, C. Schulz, and H. Wiggers, J. Electrochem. Soc. 161, A40 (2014).
[19] R. Lechner, H. Wiggers, A. Ebbers, J. Steiger, M. S. Brandt, and M. Stutzmann, Phys. Status Solidi RRL 1, 262 (2007).

[20] H. Sugimoto, M. Fujii, M. Fukuda, K. Imakita, and S. Hayashi, J. Appl. Phys. 110, 063528 (2011).

[21] A. Mimura, M. Fujii, S. Hayashi, D. Kovalev, and F. Koch, Phys. Rev. B 62, 12625 (2000).

[22] Y. Hori, S. Kano, H. Sugimoto, K. Imakita, and M. Fujii, Nano Lett. 16, 2615 (2016).

[23] P. Lu, W. Mu, J. Xu, X. Zhang, W. Zhang, W. Li, L. Xu, and K. Chen, Sci. Rep. 6, 22888 (2016).

[24] S. Zhou, X. D. Pi, Z. Y. Ni, Y. Ding, Y. Y. Jiang, C. H. Jin, C. Delerue, D. Yang, and T. Nozaki, ACS Nano 9, 378 (2015).

[25] X. D. Pi and C. Delerue, Phys. Rev. Lett. 111, 177402 (2013).

[26] D. J. Rowe, J. S. Jeong, K. A. Mkhoyan, and U. R. Kortshagen, Nano Lett. 13, 1317 (2013).

[27] N. J. Kramer, K. S. Schramke, and U. R. Kortshagen, Nano Lett. 15, 5597 (2015).

[28] Z. Y. Ni, X. D. Pi, S. Zhou, T. Nozaki, B. Grandidier, and D. Yang, Adv. Opt. Mater. 4, 700 (2016).

[29] S. Gutsch, J. Laube, D. Hiller, W. Bock, M. Wahl, M. Kopnarski, H. Gnaser, B. Puthen-Veettil, and M. Zacharias, Appl. Phys. Lett. 106, 113103 (2015).

[30] D. König, S. Gutsch, H. Gnaser, M. Wahl, M. Kopnarski, J. Göttlicher, R. Steininger, M. Zacharias, and D. Hiller, Sci. Rep. 5, 9702 (2015).

[31] T. Nakamura, S. Adachi, M. Fujii, H. Sugimoto, K. Miura, and S. Yamamoto, Phys. Rev. B 91, 165424 (2015).

[32] M. Luppi and S. Ossicini, Phys. Status Solidi A 197, 251 (2003).

[33] E. Holzenkämpfer, F. W. Richter, J. Stuke, and U. Voget-Grote, J. Non-Cryst. Solids 32, 327 (1979).

[34] A. Stirling and A. Pasquarello, Phys. Rev. B 66, 245201 (2002).

[35] D. L. Griscom, E. J. Friebele, K. J. Long, and J. W. Fleming, J. Appl. Phys. 54, 3743 (1983).

[36] R. Guerra and S. Ossicini, J. Am. Chem. Soc. 136, 4404 (2014).

[37] A. Carvalho, M. J. Rayson, and P. R. Briddon, J. Phys. Chem. C 116, 8243 (2012).

[38] Z. Y. Ni, X. D. Pi, and D. Yang, Phys. Rev. B 89, 035312 (2014).

[39] X. B. Chen, X. D. Pi, and D. Yang, J. Phys. Chem. C 115, 661 (2011). 
[40] K. Seino, F. Bechstedt, and P. Kroll, Phys. Rev. B 82, 085320 (2010).

[41] X. D. Pi, R. Wang, and D. Yang, Chin. Phys. B 23, 076102 (2014).

[42] B. Delley, J. Chem. Phys. 113, 7756 (2000).

[43] Z. Y. Ni, X. D. Pi, and D. Yang, Chin. Phys. Lett. 29, 077801 (2012).

[44] Z. Y. Ni, X. D. Pi, and D. Yang, RSC Adv. 2, 11227 (2012).

[45] X. D. Pi, R. Wang, and D. Yang, J. Mater. Sci. Technol. 30, 639 (2014).

[46] R. Wang, X. D. Pi, and D. Yang, J. Phys. Chem. C 116, 19434 (2012).

[47] X. D. Pi, Z. Y. Ni, and D. Yang, J. Appl. Phys. 116, 194304 (2014).

[48] R. A. Weeks, J. Non-Cryst. Solids 179, 1 (1994).

[49] K. Seino, F. Bechstedt, and P. Kroll, Nanotechnology 20, 135702 (2009).

[50] E. Degoli, S. Ossicini, G. Cantele, E. Luppi, R. Magri, D. Ninno, and O. Bisi, Phys. Status Solidi C 2, 3354 (2005).
[51] A. Carvalho, S. Öberg, M. J. Rayson, and P. R. Briddon, Phys. Rev. B 86, 045308 (2012).

[52] X. D. Pi, X. B. Chen, and D. Yang, J. Phys. Chem. C 115, 9838 (2011).

[53] L. G. Wang and A. Zunger, Phys. Rev. B 66, 161202 (2002).

[54] X. D. Pi, J. Nanomater. 2012, 912903 (2012).

[55] K. Fujio, M. Fujii, K. Sumida, S. Hayashi, M. Fujisawa, and H. Ohta, Appl. Phys. Lett. 93, 021920 (2008).

[56] R. Khelifi, D. Mathiot, R. Gupta, D. Muller, M. Roussel, and S. Duguay, Appl. Phys. Lett. 102, 013116 (2013).

[57] M. Xie, D. S. Li, L. Chen, F. Wang, X. D. Zhu, and D. Yang, Appl. Phys. Lett. 102, 123108 (2013).

[58] E. Degoli, G. Cantele, E. Luppi, R. Magri, D. Ninno, O. Bisi, and S. Ossicini, Phys. Rev. B 69, 155411 (2004).

[59] X. Chen, X. D. Pi, and D. Yang, J. Phys. Chem. C 114, 8774 (2010).

[60] X. Wang, R. Q. Zhang, S. T. Lee, T. Frauenheim, and T. A. Niehaus, Appl. Phys. Lett. 93, 243120 (2008). 